\title{
Morphological Variation in Spirillum spp., with Observations upon the Origin of the Hyphomicrobia
}

\author{
By K. A. BISSET \\ Department of Bacteriology, University of Birmingham
}

(Received 2 November 1960)

\begin{abstract}
SUMMARY
Pure cultures of Spirillum serpens grown on solid medium contained variants of very diverse morphological appearance; these were relatively straight rods, and branched coccobacillary and coccal forms. Flagella were in the normal lophotrichous arrangement, peritrichous, single or absent. Some forms possessed characters resembling those of the hyphomicrobia. The development of Rhodomicrobium in cultures of photosynthetic spirilla was also observed. It is suggested, not only that the spirilla possess potentialities consistent with a suggested role as the ancestral bacterial type, but also that Rhodomicrobium may be a growth form of a photosynthetic spirillum. Appearances found in the parasitic Hyphomonas polymorpha and in certain pleuropneumonia-like organisms were considered to support this concept.
\end{abstract}

\section{INTRODUCTION}

It was suggested by Bisset (1950) that the spirilla probably conform most closely to the ancestral bacterial type, and that many of the morphologically distinct types considered to have arisen from them may be regarded as adaptations to a terrestrial existence, a process paralleled in many natural groups. In support of this idea, the present paper describes a variety of morphological forms adopted by a single species of spirillum (Spirillum serpens) when cultivated on the surface of solid medium. These forms simulate many of the major characters of the hypothetically more advanced bacteria, and indicate a potential, in spirilla, for the production of such characters, in accordance with the evolutionary theory in question. The existence of a complex life-cycle in spirilla is well attested (e.g. Pease, 1956 a; Watanabe, 1959, 1960; and others). Certain of the appearances here described are attributable to phases in such a cycle, others are probably not. At the same time, some light may be thrown by these observations upon the problem of the origin and nature of the hyphomicrobia; of these three genera are recorded, each of one species, variously classified by different authorities, possessing a similar and very unusual morphology, and being credited with great versatility in their modes of life. The first descriptions of Hyphomicrobium vulgare attributed to it the power of fixing nitrogen (Rullman, 1897; Stutzer \& Hartleb, 1899), although it is now regarded as an oligotrophic saprophyte. Rhodomicrobium vannielii is considered to be a photosynthetic purple sulphur bacterium (Duchow \& Douglas, 1949). Hyphomonas polymorpha was isolated in circumstances suggestive of pathogenicity towards man (Pongratz, 1957). All these micro-organisms are distinguished by their morphology 
and mode of growth, which is quite unlike that of the recognizable forms of other bacteria, in that the cells are borne upon narrow, often ramifying filaments, and reproduce by the outgrowth of similar filaments, upon which small buds appear and grow up into new cells. The cytology of this process was described by Murray \& Douglas (1950), but the mechanism cannot be regarded as well understood. Despite the stalk-like filaments, this mode of reproduction is unlike that of the true caulobacteria, which undergo fission in a relatively normal manner (Bisset, 1955, pp. 121-4). Although true motility is possible only in small detached elements, flagella are commonly borne upon various parts of the ramifying growth, in all recognized genera. The attachment is described as polar in Hyphomicrobium vulgare (Mevius, 1953) and Hyphomonas polymorpha (Pongratz, 1957), while Douglas \& Wolfe (1959) considered the flagellation of Rhodomicrobium vannielii to be peritrichous; but the electron micrographs of Pease $(1956 \mathrm{~b})$ show polar attachment in $\boldsymbol{R}$. vannielii. Our own view is that the normal criteria of flagellar insertion must be applied with caution to micro-organisms of this morphology.

The circumstances in which Hyphomicrobium and Rhodomicrobium are usually observed are of importance in any consideration of their possible nature and relationships. They arise, in a manner for which no real explanation has hitherto been offered, in ageing and degenerate cultures of other bacteria, especially nitrifying bacteria in the first case, and photosynthetic spirilla in the second. Some strains, arising in this manner, can be isolated and subcultured, others appear to grow freely only in mixed culture.

\section{METHODS}

Observations were made upon a strain of Spirillum serpens (provided by $\mathrm{Dr}$ Phyllis Pease) which had been isolated from pond water and maintained in pure culture for 6 years; also upon four strains of Rhodomicrobium vannielii, observed in ageing cultures of photosynthetic spirilla, and two of Hyphomonas polymorpha provided by Dr E. Pongratz, by whom they were isolated from a nasal discharge.

The medium used was similar to that of Duchow \& Douglas (1949); its composition $(\%, w / v)$ was : yeast extract (Oxoid), $\mathbf{0 \cdot 2}$; sodium acetate, $0 \cdot 2$; sodium citrate, $0 \cdot 2$; ammonium sulphate, 0.1 ; magnesium sulphate, 0.01 ; di-potassium hydrogen phosphate, 0.05 ; sodium chloride, 0.2 ; at $\mathrm{pH} 7 \cdot 2$, solidified with $2 \%(\mathrm{w} / \mathrm{v})$ agar; in Petri dishes for Spirillum serpens, and dispensed in small screw-capped bottles with caps tightly fastened, for the photosynthetic forms. The organisms used grew at room temperature; Hyphomonas polymorpha grew on meat infusion agar at $37^{\circ}$.

Electron micrographs were made upon material taken directly from fluid cultures and dried upon collodion films, or from suspensions in distilled water in the case of growth on solid medium.

\section{RESULTS}

The morphology of Spirillum serpens in fluid culture, or on initial subculture on solid medium in Petri dishes, was very characteristic, consisting of spiral rods of moderate length, with a tuft of ten to fifteen flagella at each pole (Pl. 1, fig. 1). On continued subculture on solid medium the colonies lost their original smooth appearance and showed a rough spreading form. When microscopically examined, these rough colonies were seen to consist mainly of typical spirilla, but with about 20-30\% of other forms including relatively straight rods (Pl. 1, figs. 2, 4) and 
branched forms (Pl. 1, figs. 4, 5, 6). Flagellation was mainly of the normal polar type, but peritrichous arrangements were also seen, both in straight rods ( $\mathrm{Pl}$. 1, fig. 2) and in spirilla (Pl. 1, fig. 3). In the later stages of culture, after 7-10 days, typical minute swarm-cells began to appear (Pl. 1, fig. 7; cf. Pease, 1956a), some of which possessed the characteristic single polar flagellum, whereas other small rodshaped organisms were non-flagellate (Pl. 2, figs. 8, 12). In association especially with the latter were two forms of unusual appearance: $(a)$ spherical cells somewhat resembling free protoplasts, but with coiled flagella (Pl. 2, figs. 8, 9); (b) stalked cells (P1. 2, figs. 11-13). The special interest of these lay in their resemblance to hyphomicrobia (compare Pl. 2, figs. 14, 15; Pl. 3, figs. 16-18). Another type of cell arising at this stage in cultures of $S$. serpens was not exceptional in itself, being a short oval, without flagella, but once more its resemblance to certain stages in the life-cycle of hyphomicrobia was most striking (Pl. 2, fig. 10; compare Pl. 2, fig. 15).

Rhodomicrobium vannielii was observed in the later stages of crude cultures ot photosynthetic spirilla (Pl. 2, figs. 14, 15). It began to appear in cultures aged 23 weeks, and gradually increased in proportion until the entire culture was of this form, consisting of oval cells joined by narrow branched filaments. Flagella were seen on occasional cells in most fields; they were very frequently coiled (Pl. 3, figs. 16-18). As these cultures aged, after 5-6 weeks or longer, both stalks and flagella became less obvious, and the bacteria often aggregated in stellate clumps (Plate 3, figs. 18, 19). In this condition they quite closely resembled those eubacteria, including spirilla (Watanabe, 1959, 1960), which adopt a similar habit, except for the appearance of an occasional stalk or projecting filament, or more rarely a coiled flagellum. Subculture from the earlier stages of culture usually gave a mixture of hyphomicrobia and other bacteria; but after the stellate phase had commenced, the hyphomicrobia were seldom detectable in subcultures until these had again aged.

The hyphomonas strains were distinguishable from Rhodomicrobium in that they branched much less freely, and produced mainly short irregular flagella (Pl. 3, fig. 20). The characteristic form was a globular cell attached by a slender filament to a smaller cell (presumably in course of development) at the other end. For comparison, observations were made upon growth forms of pleuropneumonia-like organisms, maintained in culture in this laboratory, some of which bore a distinct resemblance to hyphomicrobia (Pl. 3, fig. 21).

\section{DISCUSSION}

The theory of bacterial evolution proposed by Bisset (1950) and subsequently elaborated (Bisset, 1955), depends for its validity upon the potentialities of spirilla as forebears of all or most of the main groups of bacteria. The postulated development of different flagellar types from polar-flagellate aquatic ancestors appears to be acceptable to certain workers in this field (Leifson, 1960, p. 18) by whom the theory has been adopted. The observations reported in the present paper provide evidence that spirilla, when constrained to adopt an unnatural mode of existence on solid medium, may produce morphological forms which simulate, in certain respects, those bacteria whose morphology is believed to be an adaptation of the original spirillar form to a terrestrial environment. The appearance of straight or 
branched rods with typically spirillar flagella, or of peritrichous flagella upon spiral rods, may be regarded as indicating that all these variant characters are separately associable with the problem of adaptation to terrestrial environments. At the same time, the mixture of normal and variant characters in these organisms serves to confirm their identity with the original strain. This obviation of any suggestion of contamination is important also in consideration of the stalked forms, and others resembling hyphomicrobia, which occur in the latter stages of culture. The accepted theory of origin of hyphomicrobia is that they exist as contaminants in cultures of autotrophic bacteria, which they eventually overgrow. However, the existence of comparable forms in pure cultures of spirilla, and the peculiarities of the lifecycle of strains of Rhodomicrobium derived in the normal way from cultures of photosynthetic spirilla, render it at least equally probable that Rhodomicrobium also is a variant or growth form of a Rhodospirillum. These observations are not unique, in that Watanabe (1959) not only illustrates spirilla in stellate clusters of the appearance of those adopted by Rhodomicrobium, but also forms derived from the growth-cycle of saprophytic spirilla that bear a strong resemblance to hyphomicrobia. It is significant that hyphomicrobial morphology can be adopted by the parasitic Hyphomonas polymorpha, which also has flagella of degenerate appearance. The coiled flagella found in Rhodomicrobium and in the hyphomicrobial forms of Spirillum serpens occur in other bacterial groups (Leifson, 1960), but are especially distinctive of Rhodomicrobium. The resemblance already noted between hyphomicrobia and certain stages of pleuropneumonia-like organisms is demonstrated with even greater clarity in the figures of Ledingham (1933) and Turner (1935). It may perhaps be stated, without further elaborating the argument here, that these organisms are now accepted by some workers to be growth forms of true bacteria. Thus it would appear that the adoption of a morphology of this type is quite widespread among bacteria of different groups.

In view of the suggestion already made, in support of the evolutionary concept quoted at the beginning of this discussion, that the variant forms described here are adaptations to growth on solid medium, it is interesting to consider that the hyphomicrobial morphology is adapted to growth in attachment to solid surfaces, usually the sides of vessels containing fluid medium. Even the very small swarm cells, with their single polar flagella, are capable of motility in the thin film of moisture on an agar surface, where normal spirilla are usually completely immobilized. In appearance, these swarmers closely resembled vibrios, and although not strictly variants as in the case of the bacillary branched peritrichously-flagellate or hyphomicrobial forms, they afford further evidence of the ability of spirilla to produce or simulate most of the characters of the bacterial groups to which, on the hypothesis of Bisset $(1950,1955)$, they may be considered as ancestral.

\section{REFERENCES}

Bisset, K. A. (1950). Evolution in bacteria and the significance of the bacterial spore. Nature, Lond. 166, 431.

Bisset, K. A. (1955). The Cytology and Life-History of Bacteria. Edinburgh: Livingstone. Douglas, H. C. \& Wolfe, R. S. (1959). Motility of Rhodomicrobium vanniellii. J. Bact. 78, 597.

Duchow, E. \& Douglas, H. C. (1949). Rhodomicrobium vannielii, a new photoheterotrophic bacterium. J. Bact. 58, 409. 

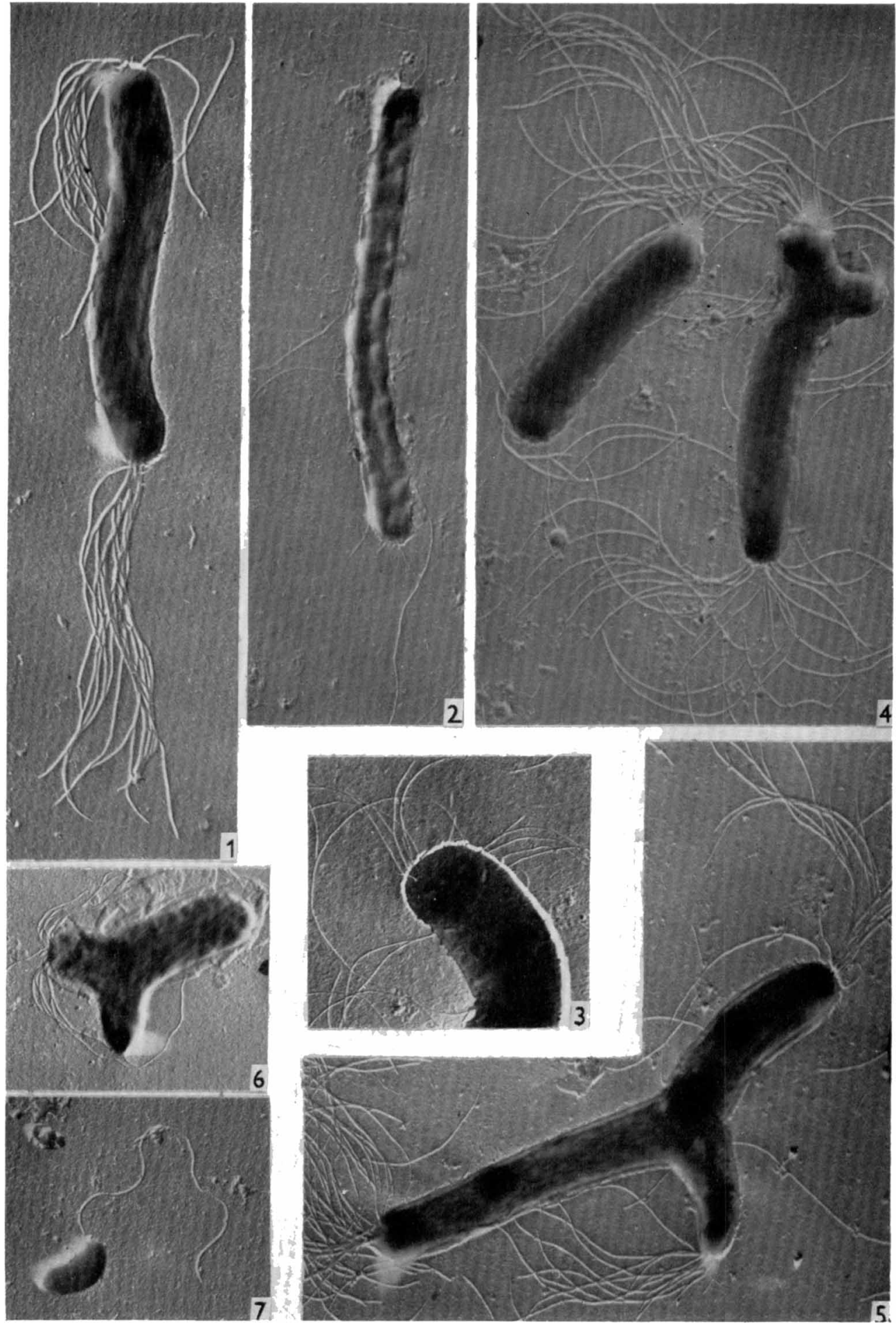

K. $A$, BISSET 

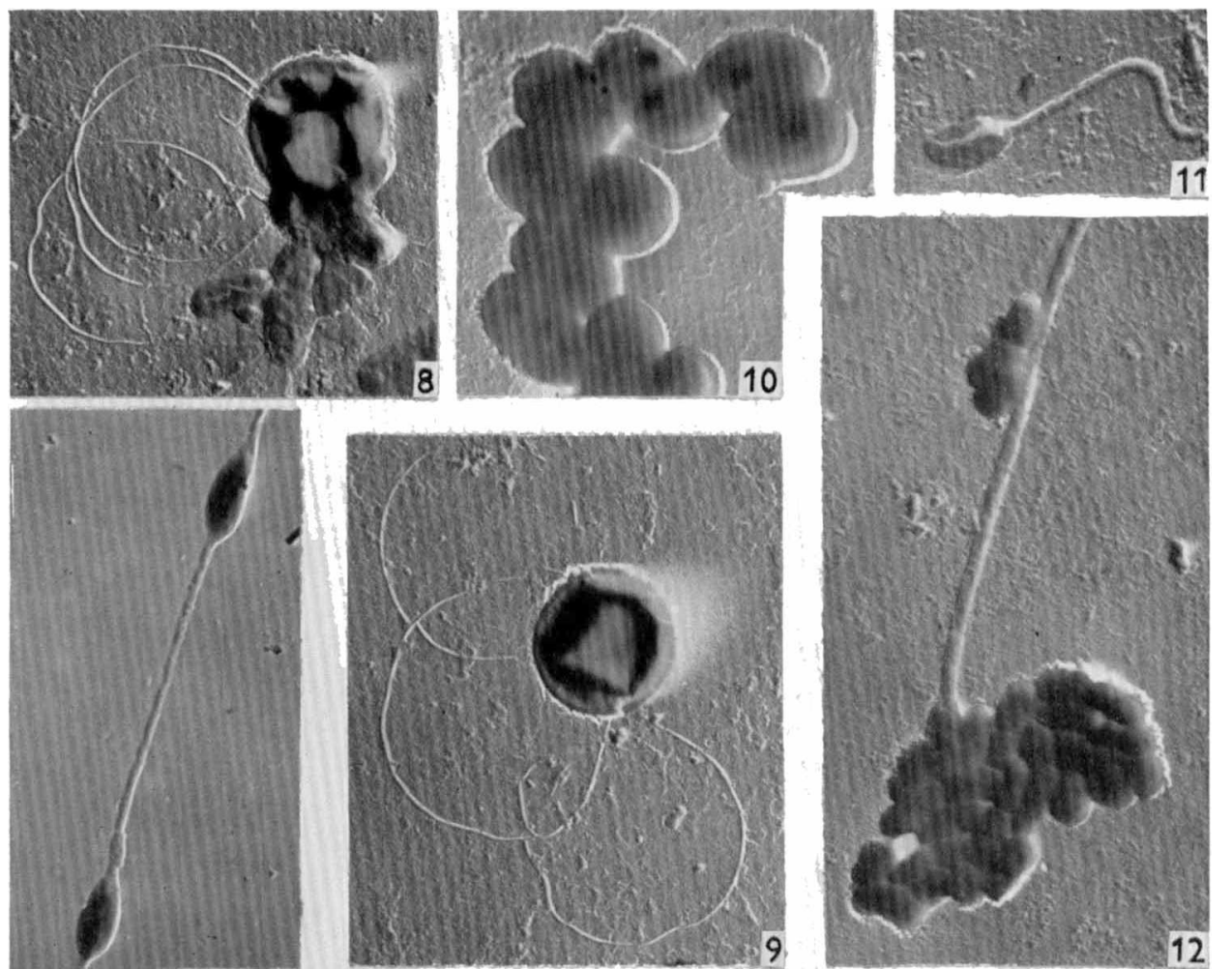

9
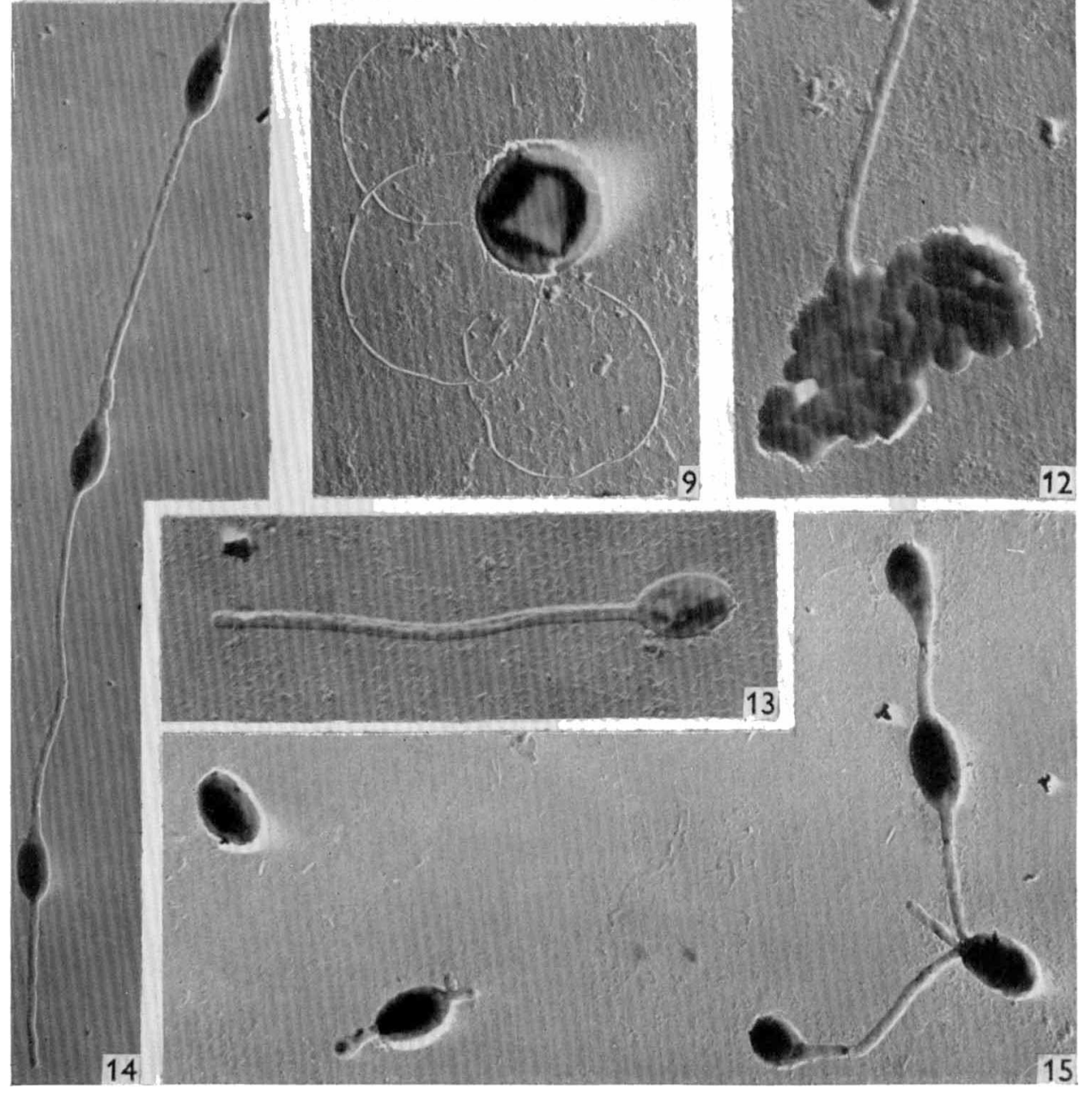

K. A. BISSET 


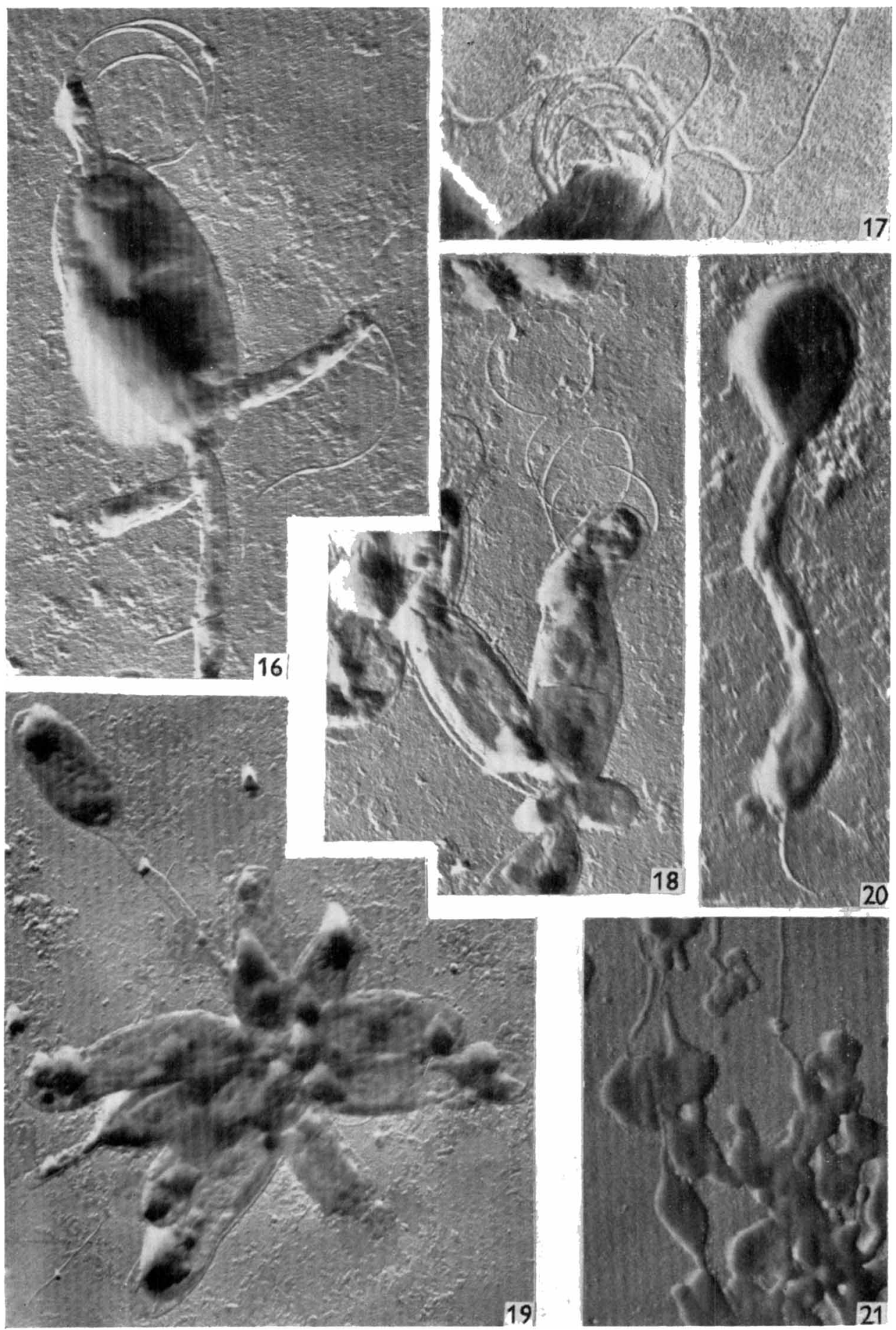

K, A, BISSET 
Ledingham, J. C. G. (1933). The growth phases of pleuropneumonia and agalactia on liquid and solid media. J. Path. Bact. 37, 393.

LEIfson, E. (1960). Atlas of Bacterial Flagellation. New York: Academic Press Inc.

Mevius, W. (1953). Beiträge zur Kenntnis von Hyphomicrobium vulgare, Stutzer et Hartleb. Arch. Mikrobiol. 19, 1.

Murray, R. G. E. \& Douglas, H. C. (1950). The reproductive mechanism of Rhodomicrobium vannielii and the accompanying nuclear changes. J. Bact. 59, 157.

Pease, P. E. $(1956 a)$. The gonidial stages in Spirillum spp. and Vibrio spp. J. gen. Microbiol. 14, 672.

Pease, P. E. (1956b). Electron micrographs in thesis: Rhodomicrobium, by C. F. Lucas, University of Birmingham.

Pongratz, E. (1957). D'une bactérie pédiculée isolée d'un pus de sinus. Schweiz. Z. allg. Path. Bakt. 20, 593.

Rullman, W. (1897). Über ein Nitrosobakterium mit neuen Wuchsformen. Z Zbl. Bakt. (2 $A b t$.), 3, 228.

Stutzer, A. \& Hartleb, R. (1899). Untersuchungen über die bei Bildung von Salpeter beobachteten Microorganismen. Zbl. Bakt. (2. Abt. Ref.), 5, 678.

Turner, A. W. (1935). A study on the morphology and life-cycles of the organisms of Pleuropneumonia contagiosa boum (Borrelomyces peripneumoniae nov. gen.) by observation in the living state under dark ground illumination.

Watanabe, N. (1959). On the life cycle of Spirillum maritimum. J. Res. (Kenkyu Kiyo), Fac. Educ., Chiba Univ. 8, 91.

W atanabe, N. (1960). On the life cycle of Spirillum maritimum. Bot. Mag. Tokyo, 73, 44.

\section{EXPLANATION OF PLATES}

(All figures are electron micrographs, gold-palladium shadowed.)

Plate 1

Fig. 1. Spirillum serpens: normal appearance, spiral with polar flagella. $\times 10,000$.

Fig. 2. S. serpens: rod form with irregular peritrichous flagella. $\times 10,000$.

Fig. 3. S. serpens: spiral form with peritrichous flagella. $\times 10,000$.

Fig. 4. S. serpens: straight and branched rods with polar flagella. $\times 10,000$.

Figs. 5, 6. S. serpens: branched rods with polar flagella. $\times 10,000$.

Fig. 7. S. serpens: swarmer cell, with single flagellum. $\times 10,000$.

\section{Plate 2}

Figs. 8, 9. Spirillum serpens: spherical cells (protoplasts?) associated with swarmers, showing coiled flagella. $\times 10,000$.

Fig. 10. S. serpens: non-flagellate oval cells (compare fig. 15). $\times 10,000$.

Figs. 11-13. S. serpens: stalked forms associated with swarmers (compare figs. 14, 15). $\quad \times 10,000$.

Figs. 14, 15. Rhodomicrobium vannielii : branched filaments and individual cells (compare figs. 1013). $\times 7,500$.

\section{Plate 3}

Figs. 16, 17. R. vannielii: showing coiled flagella. $\times 20,000$.

Figs. 18, 19. R. vannielii : stellate clumps, mainly bacillary forms, with occasional stalks and coiled flagella. $\times 10,000$.

Fig. 20. Hyphomonas polymorpha: cell with short filament and bud bearing single, short flagellum. $\times 20,000$.

Fig. 21. Organism of contagious agalactia (goat) showing hyphomicrobial forms. $\times 15,000$. 